\title{
Correction of collector efficiency depending on fluid type, flow rate and collector tilt IEA-SHC TECH SHEET 45.A.1, page 1 of 21
}

Correction of collector efficiency depending on variations of collector type, solar

Subject:

Date: collector fluid, volume flow rate and collector tilt

22 December 2014

Influence and importance of variations of collector type, solar collector fluid,

Description: volume flow rate and collector tilt on the efficiencies and thermal performances of collectors.

Federico Bava \& Simon Furbo, Technical University of Denmark and Alfred Brunger, EXOVA, Canada

Download possible at: http://task45.iea-shc.org/fact-sheets

\section{Contents}

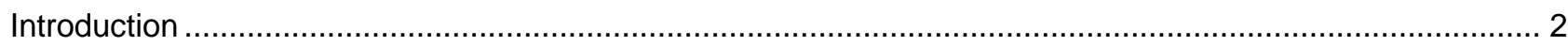

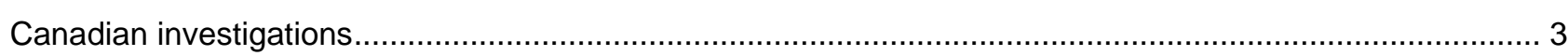

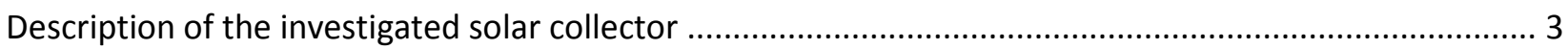

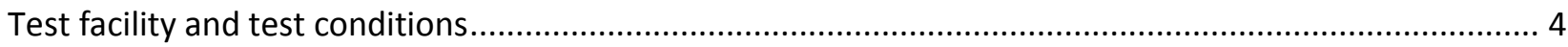

Collector efficiency for different volume flow rates ............................................................ 6

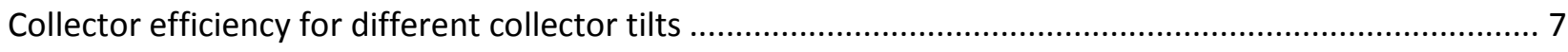

Collector efficiency for different solar collector fluids ................................................................ 9

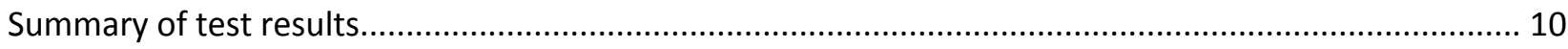

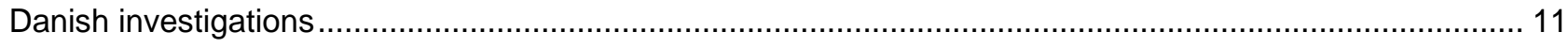

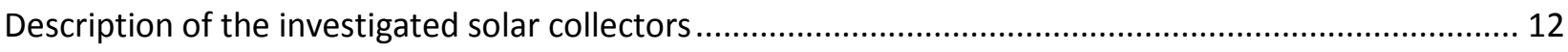

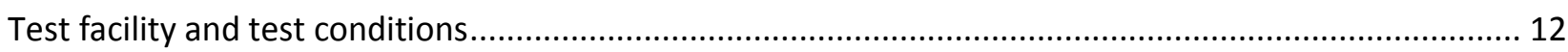

Influence of the FEP foil on the collector efficiency .................................................................... 14

Collector efficiencies for different volume flow rates.............................................................. 14

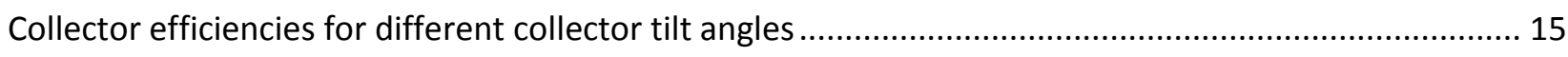

Collector efficiencies for different solar collector fluids .......................................................... 16

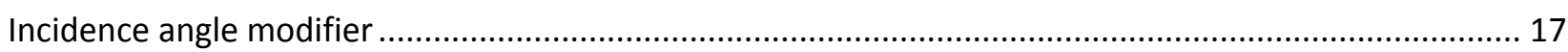

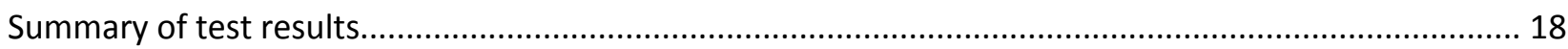

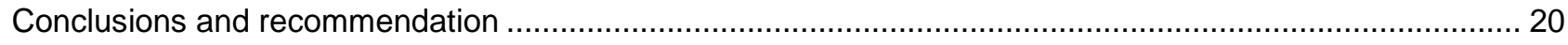

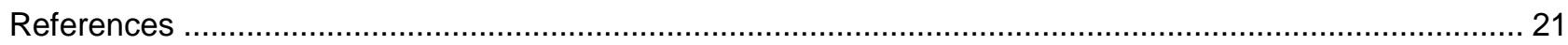




\section{Correction of collector efficiency depending on fluid type, flow rate and collector tilt \\ IEA-SHC TECH SHEET 45.A.1, page 2 of 21}

\section{Introduction}

In its basic form, a solar thermal collector is designed to intercept solar radiation, absorb that radiation to convert it into heat energy, and then deliver that heat to a heat transfer fluid. Therefore, the performance of a solar thermal collector is influenced by all variables that affect either the optical or the thermal properties of the collector. For example, the incidence angle of solar radiation onto the solar collector can affect the optical performance of the collector. While typically not a strong factor for solar thermal collectors, the changing spectral quality of sunlight with changing atmospheric conditions can influence the fraction of the incoming solar radiation that gets transmitted and absorbed by the collector. Tilt angle, especially for glazed flat plate collectors, affects internal and external convective heat transfer coefficients, and thus influences collector thermal performance. Heat transfer fluid flow rate and fluid thermal properties influence the heat transfer coefficient inside the fluid passages of the collector, and thus influence the collector efficiency.

Solar collector data sheets released by test institutes usually state the collector efficiency only for one operating condition, which can differ significantly from those actually used in solar heating systems, so the actual thermal performance of the collector cannot be known in advance. This study focused on the experimental test of three solar collectors, in different conditions of flow rate, collector tilt angle and fluid type, to verify the influence that each parameter has on the collector efficiency and access the error which is introduced when the collector efficiency from the technical data sheet is used in place of one evaluated under more realistic operating conditions.

In the first part of the study, the thermal performance of a single flat plate collector was measured with two different heat transfer fluids, two different tilt angles, and three different fluid flow rates. Tests were conducted with twelve different combinations of these three parameters, and the results have been used to quantify the effects of these variables on the thermal performance of the solar collector. The results of the tests are presented in detail in the section "Canadian investigations".

In the second part of the study (section "Danish investigations") two large solar collectors were investigated, more specifically the models HT-SA 35-10 and HT-A 35-10, manufactured by the Danish company ARCON Solar A/S. These collectors have large aperture area (about $12.5 \mathrm{~m}^{2}$ ) and they are installed in large number in solar collector fields for district heating purposes. This kind of installation is very common in Denmark, where more than 50 collector fields could be found at the end of 2014, the largest of which has a collector area of 37,573 square meters (Dronninglund field).

The two ARCON collectors were identical with the only difference being a FEP (fluorinated ethylene propylene) foil interposed between the absorbing plate and the glass cover in the model HT-SA. The presence of the FEP foil is expected to reduce the convection losses, as the air between the absorber and the glass circulates in two different layers of convective cells, one above and the other below the foil. The heat losses from the collector cover are therefore lower than in the collector without foil, due to the additional thermal resistance given by the convective heat transfer coefficient between the air and the FEP foil. Nevertheless, as the foil is not completely transparent, it slightly reduces the solar irradiance reaching 


\section{Correction of collector efficiency depending on fluid type, flow rate and collector tilt \\ IEA-SHC TECH SHEET 45.A.1, page 3 of 21}

the absorber. Consequently, there is a certain operating temperature below which the collector without foil performs better than the other, as the transmittance of the cover plays a more significant role than the thermal losses.

The technical specification sheets (Arcon Solar, 2010; SP Technical Research Institute of Sweden, 2011) state the collector efficiency when a 25 litres $\min ^{-1}$ flow rate of pure water is supplied to a $60^{\circ}$ tilted collector, conditions which are very unlikely to be found in a Danish solar collector field. For this reason, the two collectors were tested at different flow rates and tilt angles, using a mixture of propylene glycol (PG) and water with a mass concentration of $40 \%$ PG. In fact, the efficiency of a solar collector is influenced by the volume flow rate, as shown by Chiou (1982) and Wang and Wu (1990) for vertical pipe collectors and by Fan and Furbo (2008) for horizontal pipe collectors. The influence of the tilt on collector efficiency was investigated by Furbo and Holck (1995).

The experimental determination of the collector efficiency equation is of key importance when assessing the actual performance of the collectors in certain operating conditions. As experimental tests are usually time consuming and expensive, it may be useful to have a model that is able to estimate the collector efficiency, so that it can be used to predict its value also under conditions that differ from those tested. In this study, such a model was created in Soleff, software developed at Technical University of Denmark (Rasmussen and Svendsen, 1996), and compared to the experimental measurements. The results of the simulation models and the comparison with the experimental efficiencies are presented in the section "Analyses on prediction methods to determine efficiencies for collectors in operation in solar collector fields".

\section{Canadian investigations}

\section{Description of the investigated solar collector}

The collector selected for the tests was the model of collector used in the Drake Landing Solar Community project in Alberta, Canada. Detailed information for the collector is listed below. A photograph of the collector under test in the NSTF is shown in Figure 2.1.

$\begin{array}{ll}\text { Manufacturer:EnerWorks Inc., Canada } \\ \text { Collector Model: } & \text { COL-4X8-NL-SGI-SH10 } \\ \text { Serial Number: } & 1202064 \\ \text { Collector Type: } & \text { Glazed flat plate, liquid-heating, serpentine flow pattern } \\ \text { General Construction }{ }^{1}: & \text { Carbon steel frame w/Galvalume coating, aluminum back sheet. } \\ \text { Flow Pattern: } & \text { Serpentine with internal headers } \\ \text { Serpentine tubes }{ }^{1}: & 10 \mathrm{~mm} \text { OD }(9 \mathrm{~mm} \text { ID) copper tube } \\ \text { Internal headers }^{1:} & 22 \mathrm{~mm} \text { OD }(21 \mathrm{~mm} \mathrm{ID)} \text { copper pipe }\end{array}$

\footnotetext{
${ }^{1}$ Information supplied by the manufacturer.
} 


\section{Correction of collector efficiency depending on fluid type, flow rate and collector tilt \\ IEA-SHC TECH SHEET 45.A.1, page 4 of 21}

Cover Plate ${ }^{1}$ :

Absorber Material ${ }^{1}$ :

Absorber Coating ${ }^{1}$ :

Gross Dimensions:

Insulation ${ }^{1}$ :

Dry Weight ${ }^{1}$ :

Mounting Details:
AFG Solatex tempered glass, $3.3 \mathrm{~mm}$ thick, sand pattern

$0.5 \mathrm{~mm}$ thick aluminum

Miro-therm coated front surface, corrosion resistant nickel based coating on rear surface.

$2.442 \mathrm{~m} \times 1.175 \mathrm{~m}$; Area: $2.869 \mathrm{~m}^{2}$

$1-3 / 8$ " thick mineral wool back insulation, protected by 0.016 " thick aluminum sheet on the outside. 1 " thick polyisocyanurate foam edge insulation.

$50 \mathrm{~kg}$.

Attached to test frame with Unistrut
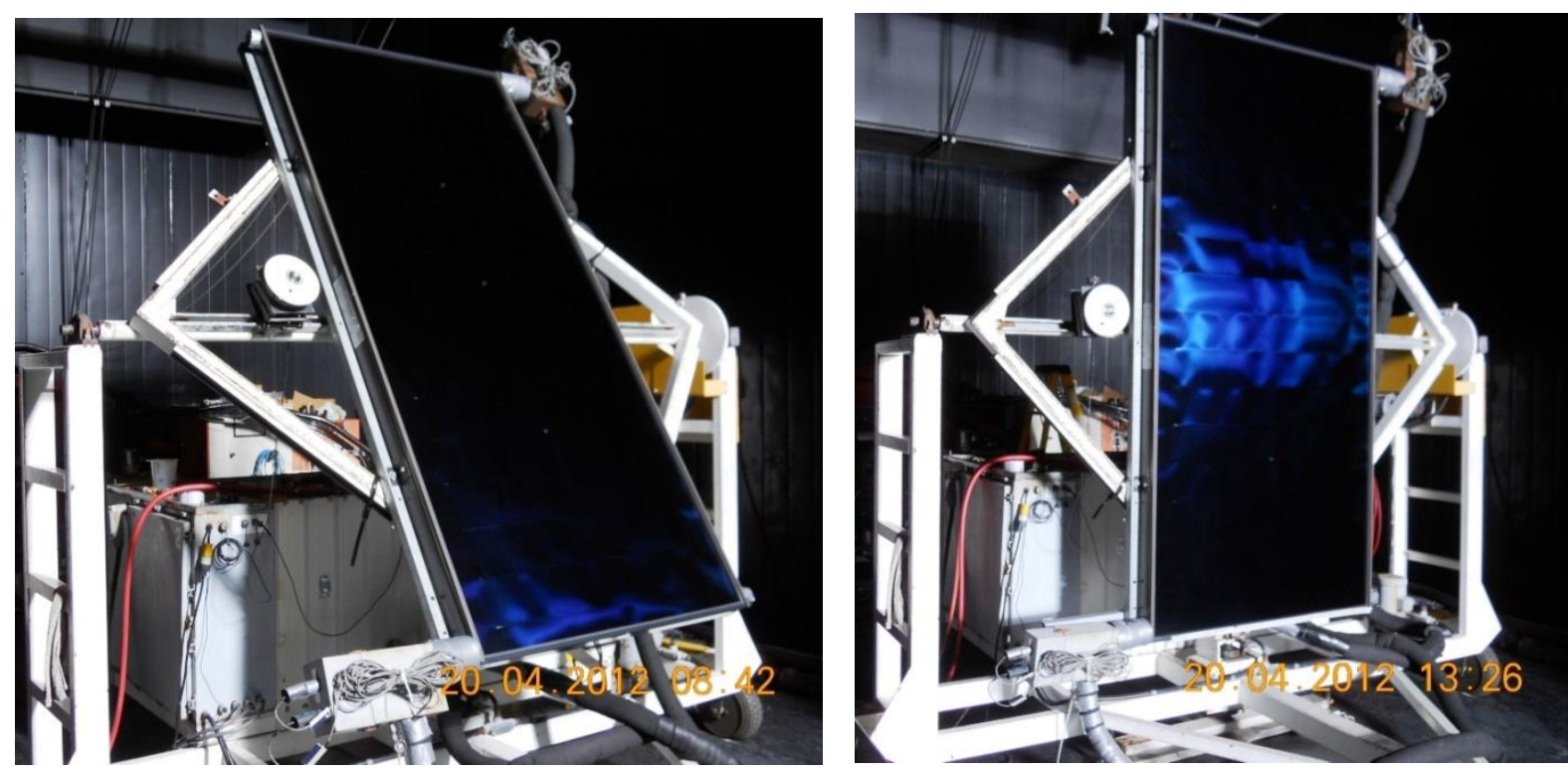

Figure 2.1: Test collector mounted in the solar simulator chamber, showing the two different mounting positions.

\section{Test facility and test conditions}

The Canadian test plan was designed to quantify the effects of tilt angle, flow rate, and fluid type on the efficiency of a liquid-heating glazed flat plate collector. All the tests were carried out indoors in the large area solar simulator at the National Solar Test Facility of Canada (NSTF), located at the Exova Technology Centre in Mississauga, Ontario. The solar simulator shines into an environmental chamber where the test collector is mounted. Wind generators on either side of the solar irradiance window provide constant wind speed conditions with turbulence characteristics designed to match natural outdoor wind. Air temperature, irradiance and wind speed can be controlled to various setpoints, and held constant during testing.

To reduce the number of parameters to vary and analyze, we endeavored to keep the solar irradiance and wind speed constant during the tests. With three independent variables considered for the tests, and 


\section{Correction of collector efficiency depending on fluid type, flow rate and collector tilt \\ IEA-SHC TECH SHEET 45.A.1, page 5 of 21}

multiple levels desired for each of the parameters, a full factorial experiment with three levels of each parameter would require 27 different thermal performance tests on the same collector. To save on testing resources while still covering the main objectives of our tests, we reduced the number of levels of tilt angle and fluid type, as shown in Table 2.1.

For all the tests, the solar irradiance was kept at $810 \mathrm{~W} / \mathrm{m}^{2} \pm 10 \mathrm{~W} / \mathrm{m}^{2}$ and the wind generators were kept running a constant speed. An unintended consequence of keeping the wind generators set at the same RPM was that the average wind speed over the face of the collector was lower when the collector was vertical than when the collector was tilted back to 60 degrees from horizontal. For the vertical collector tests, the average wind speed was $2.6 \mathrm{~m} / \mathrm{s}$. For the tests with the collector at a 60 degree tilt, the average wind speed was $3.9 \mathrm{~m} / \mathrm{s}$. As a result, the effect of tilt angle was confounded with the effect of wind speed in these tests.

Table 2.1: Summary of Test Plan for Canadian Investigations

\begin{tabular}{|c|c|c|c|c|c|}
\hline Test No. & $\begin{array}{c}\text { Test } \\
\text { Fluid }\end{array}$ & $\begin{array}{c}\text { Flow Rate } \\
(\mathbf{L} / \mathrm{min})\end{array}$ & $\begin{array}{c}\text { Flow Rate } \\
(\mathbf{k g} / \mathbf{s})\end{array}$ & $\begin{array}{c}\text { Tilt Angle } \\
\text { (degrees) }\end{array}$ & $\begin{array}{c}\text { Order to } \\
\text { Perform Test }\end{array}$ \\
\hline 1 & Water & 0.18 & 0.003 & 60 & $\mathrm{C}$ \\
\hline 2 & Water & 1.20 & 0.020 & 60 & $\mathrm{D}$ \\
\hline 3 & Water & 3.44 & 0.057 & 60 & $\mathrm{~A}$ \\
\hline 4 & Water & 0.18 & 0.003 & 90 & $\mathrm{~F}$ \\
\hline 5 & Water & 1.20 & 0.020 & 90 & $\mathrm{E}$ \\
\hline 6 & Water & 3.44 & 0.057 & 90 & $\mathrm{~B}$ \\
\hline 7 & $50 \%$ PG & $0.18 \dagger^{\dagger}$ & $0.003^{\prime}$ & 60 & $\mathrm{~J}$ \\
\hline 8 & $50 \%$ PG & $1.2^{\dagger}$ & $0.02^{\prime}$ & 60 & $\mathrm{I}$ \\
\hline 9 & $50 \%$ PG & $3.4 \dagger^{\dagger}$ & $0.0573^{\prime}$ & 60 & $\mathrm{G}$ \\
\hline 10 & $50 \%$ PG & $0.18^{*}$ & $0.003^{*}$ & 60 & $\mathrm{H}$ \\
\hline 11 & $50 \%$ PG & $1.2^{*}$ & $0.02^{*}$ & 60 & $\mathrm{~K}$ \\
\hline 12 & $50 \%$ PG & $3.44^{*}$ & $0.0573^{*}$ & 60 & $\mathrm{~L}$ \\
\hline
\end{tabular}

${ }^{\dagger}$ For these three tests, the mass flow rate was kept the same as the setting for water.

* For these three tests, the product of mass flow and thermal capacitance $(\mathrm{m} \bullet \mathrm{Cp})$ was matched to the $(\mathrm{m} \bullet \mathrm{Cp})$ used for the corresponding tests with water.

Three flow rates were chosen to try to cover as wide a range as possible, while keeping the solar irradiance the same for all tests. Three levels of flow rate is the minimum number we could use to get a measure of the non-linearity of the flow rate effect. Two fluid types were chosen: water and a $50 \%$ solution of 


\section{Correction of collector efficiency depending on fluid type, flow rate and collector tilt \\ IEA-SHC TECH SHEET 45.A.1, page 6 of 21}

propylene glycol (PG). Due to the limited range of tilt angles possible within the confines of the solar simulator, only two tilt angles ( 60 and 90 degrees from horizontal) were chosen for the tests.

Twelve tests were defined: six using water as the heat transfer fluid, and six using a 50\% solution of PG and water. The order that the tests were performed was randomized within each group of six tests with the same heat transfer fluid, to reduce any unintentional correlation between successive tests. The order that the tests were performed in is the alphabetical order of the tests listed in the right-most column of Table 2.1.

The six tests that were done with 50\% PG as the heat transfer fluid were all done with a collector tilt angle of 60 degrees from horizontal. Three of those tests were done with volume flow rates equal to the volume flow rate that were used for the tests with water as the heat transfer fluid, and the other three tests were done with the same product of mass flow rate and fluid thermal capacitance $(m \bullet C p)$ as the corresponding tests with water. This was done so that we could more directly evaluate the effect of using different fluids, independent of the capacity of the fluid to carry heat out of the collector.

The majority of the collector test was carried out at four different inlet temperatures of $25^{\circ} \mathrm{C}, 45{ }^{\circ} \mathrm{C}, 65^{\circ} \mathrm{C}$ and $85^{\circ} \mathrm{C}$. For the tests carried out at the lowest flow rate of $0.01 \mathrm{~kg} \bullet \mathrm{s}^{-1}$, the highest inlet temperature we used was $80^{\circ} \mathrm{C}$ so that the fluid outlet temperature would stay below $100{ }^{\circ} \mathrm{C}$. At each of the four inlet temperature conditions, four periods of five-minute data were collected and averaged to provide a total of 16 data points from which to calculate a collector efficiency equation for the collector.

Both linear and nonlinear efficiency curve coefficients were calculated from the raw measurements. An example of the test data for the highest water flow rate is printed on the following page. The efficiency coefficients were based on a gross collector area of $2.869 \mathrm{~m}^{2}$ and a reduced temperature difference $\left(\Delta \mathrm{T}^{*}\right)$ based on mean collector temperature.

$$
\Delta T^{*}=(T m-T a) / G
$$

$\mathrm{Tm}=$ average of heat transfer fluid inlet and outlet temperature $\left({ }^{\circ} \mathrm{C}\right)$

$\mathrm{Ta}=$ ambient air temperature $\left({ }^{\circ} \mathrm{C}\right)$

$\mathrm{G}=$ Solar irradiance on the aperture of the solar collector $\left(\mathrm{W} / \mathrm{m}^{2}\right)$

\section{Collector efficiency for different volume flow rates}

In the Drake Landing Solar Community (DLSC) project, the flow rate varied between $5 \%$ and $35 \%$ of the commonly-applied standard collector test flow rate of $0.02 \mathrm{~kg} \bullet \mathrm{s}^{-1} \bullet \mathrm{m}^{-2}$. The lowest flow rates are used at DLSC when the solar irradiance is low and the inlet temperature to the solar collector array is high. In our study, we were not able to use as low a flow rate as used at DLSC, because of the requirement in our study to keep the solar irradiance constant at $800 \mathrm{~W} / \mathrm{m}^{2}$. Figure 2.2 shows how the fluid temperature rise in the collector varies with flow rate. To keep the fluid in the test collector below boiling temperature, while still allowing a workable range of inlet fluid temperatures, we chose total mass flow rates of water between 


\section{Correction of collector efficiency depending on fluid type, flow rate and collector tilt \\ IEA-SHC TECH SHEET 45.A.1, page 7 of 21}

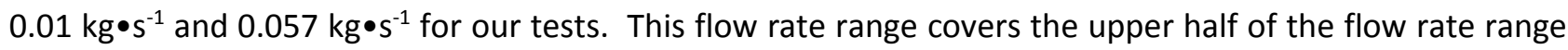

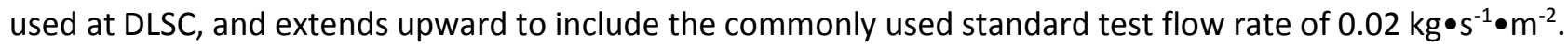

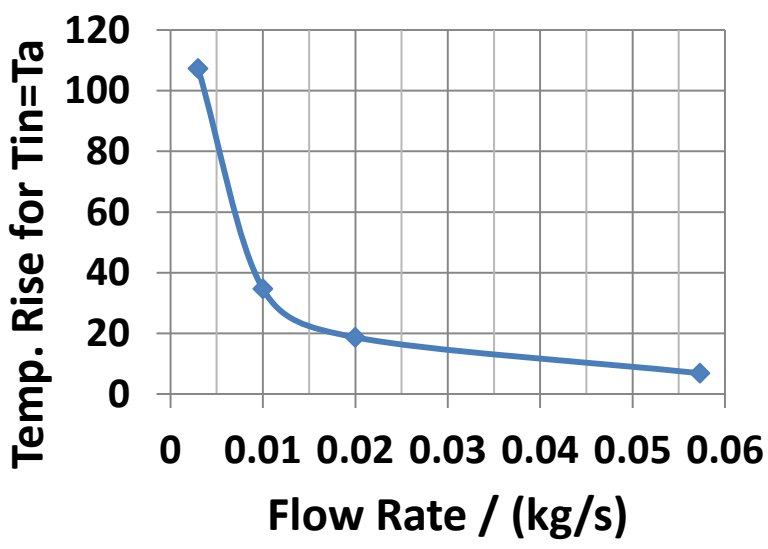

Figure 2.2: Predicted collector fluid temperature rise for various flow rates.

Fluid flow rate is commonly considered in North America to be the variable most influential on the efficiency of a liquid-heating glazed collector. This is because the North American convention is to describe collector efficiency as a function of reduced temperature based on inlet fluid temperature rather than mean fluid temperature. That is,

$$
\Delta \mathrm{T}^{* *}=(\mathrm{Ti}-\mathrm{Ta}) / \mathrm{G}, \quad \text { rather than } \Delta \mathrm{T}^{*}=(\mathrm{Tm}-\mathrm{Ta}) / \mathrm{G} \text {. }
$$

Indeed, when efficiency is based on $\Delta T^{* *}$, the intercept efficiency increases an average of $12 \%$ over the 5.7 fold increase in water flow rate considered in this study, and the collector heat loss coefficient increases by $11 \%$. In contrast, when the efficiency is based on $\Delta T^{*}$, the dependence of the heat loss coefficient on water flow rate becomes negligible $(-0.4 \%)$, and the dependence of intercept efficiency on water flow rate is reduced to less than $2 \%$.

The slope and intercept of the linear efficiency curves using water as the heat transfer fluid are plotted in Figure 2.3 to visually show the effect of varying the collector fluid flow rate. When collector efficiency is related to mean fluid temperature, it is apparent that there is a negligible effect on both intercept efficiency and heat loss coefficient.

The result is somewhat different when $50 \%$ PG is used as the heat transfer fluid. These results are plotted in Figure 2.4, and they show an increase in collector efficiency with increase in fluid flow rate. The intercept efficiency increases an average of $5.8 \%$ and the heat loss term increases by $3.6 \%$. This may be attributable to Reynolds number effects, as is discussed below.

\section{Collector efficiency for different collector tilts}

The slope and intercept of the linear efficiency curves for the six tests with water as the heat transfer fluid are plotted in Figure 2.5 as a function of tilt angle. These test results show that tilt angle only affects the 


\section{Correction of collector efficiency depending on fluid type, flow rate and collector tilt \\ IEA-SHC TECH SHEET 45.A.1, page 8 of 21}

heat loss coefficient, which decreases with tilt angle from horizontal by $7 \%$ on average over the limited range of these tests. The intercept efficiency decreases slightly-only $0.7 \%$ on average, which is likely comparable to the repeatability of the measurements.
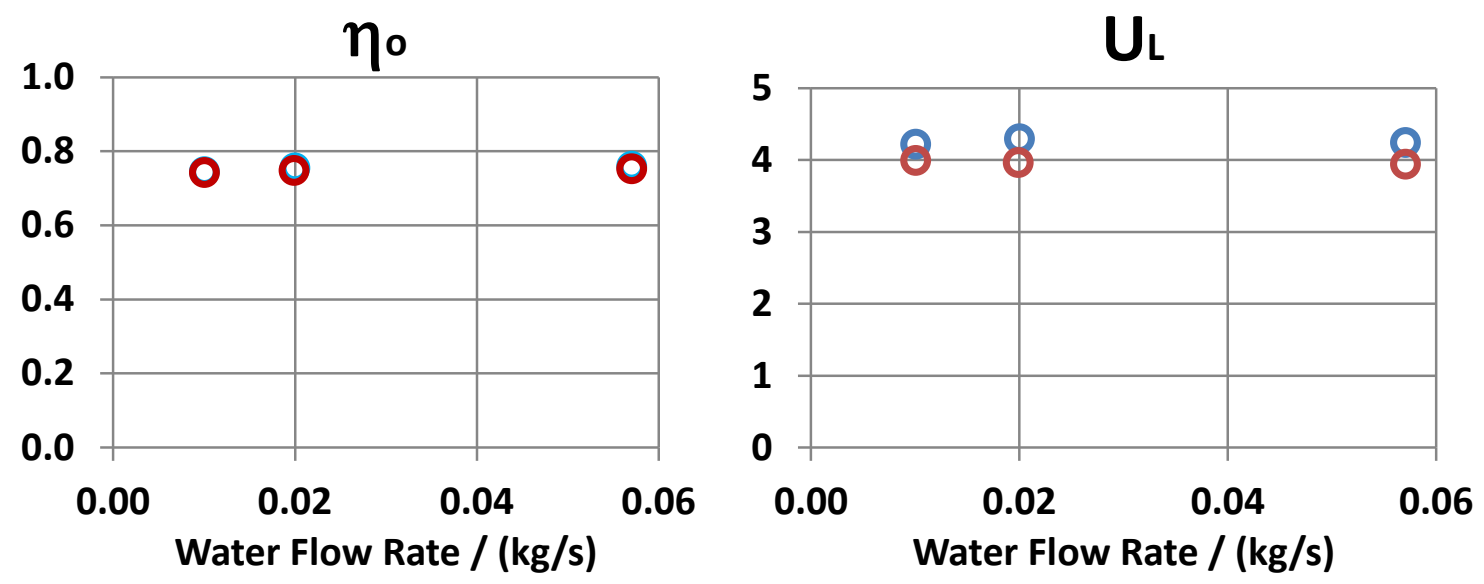

Figure 2.3: Collector efficiency linear coefficients for various flow rates of water. Red circles are for the vertical collector and blue circles are for the collector at $60^{\circ}$ tilt.
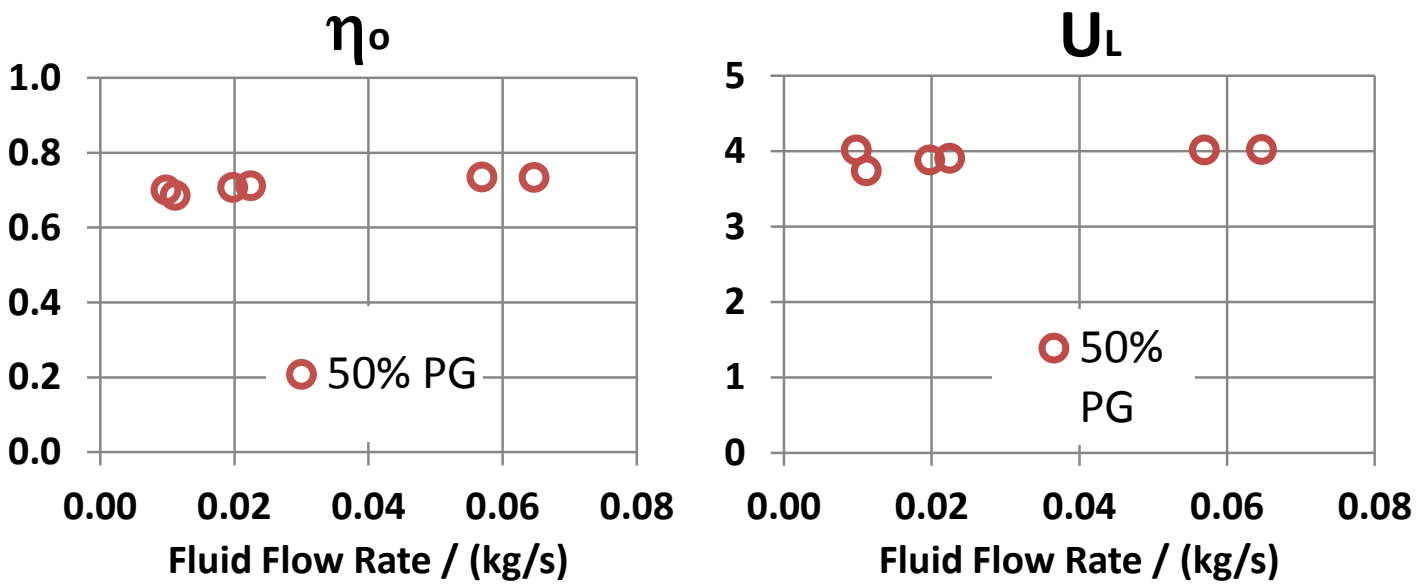

Figure 2.4: Collector efficiency linear coefficients for various test flow rates of 50\% PG. All data are for the collector at $60^{\circ}$ tilt.

It is to be expected that the collector heat loss from the glazing would be less for the vertical collector than for the collector tilted at 60 degrees, because the convective heat transfer between the cool glazing and the hot absorber plate will be less in a vertical air space. However, as mentioned previously, the collector in the vertical orientation was tested at a lower average wind speed over its aperture. The observed reduction in heat loss from the collector may therefore be attributed to both lower internal and external convective heat transfer. Detailed modeling of the top heat loss from the collector, including estimates of 


\section{Correction of collector efficiency depending on fluid type, flow rate and collector tilt \\ IEA-SHC TECH SHEET 45.A.1, page 9 of 21}

both the internal and external convection heat transfer, would be required to separate the observed effect into an effect of wind speed and an effect of tilt angle.
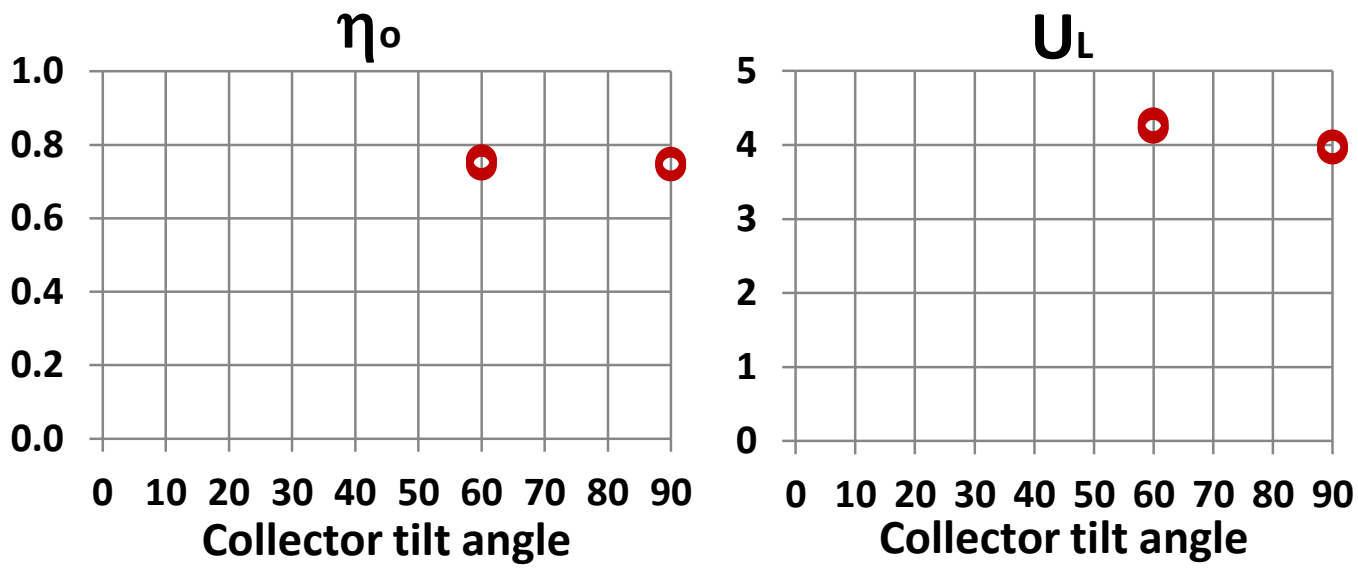

Figure 2.5: Collector efficiency linear coefficients for two different tilt angles.

Collector efficiency for different solar collector fluids

Three of the tests with $50 \%$ propylene glycol (PG) as the heat transfer fluid were performed with mass flow rates equal to the mass flow rates used in the tests with water. The other three tests with $50 \%$ PG were performed with higher flow rates, so that the product of mass flow rate times fluid thermal capacitance $(\mathrm{m} \bullet \mathrm{Cp})$ was the same as for the tests with water. In this way, we attempted to separate the effect of the heat carrying capacity of the fluid from other effects. The results are plotted in Figure 2.6.
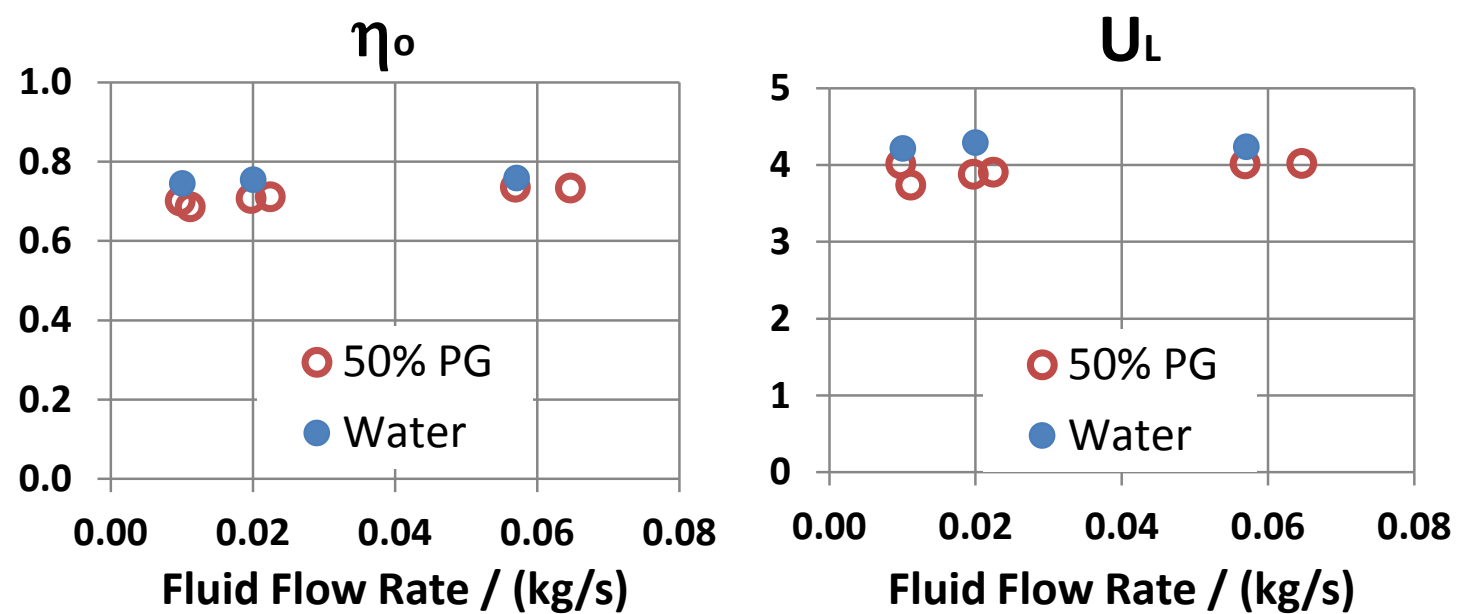

Figure 2.6: Comparison of collector efficiency linear coefficients for two different heat transfer fluids and for a range of test flow rates. 


\section{Correction of collector efficiency depending on fluid type, flow rate and collector tilt \\ IEA-SHC TECH SHEET 45.A.1, page 10 of 21}

The obvious effect of using $50 \%$ PG is that the performance of the collector is reduced compared to using water as the heat transfer fluid. That result holds whether the mass flow rate is held constant or whether the product of $(\mathrm{m} \cdot \mathrm{Cp})$ is held constant. When the mass flow rate is the same between the tests, the average intercept efficiency is $5.3 \%$ lower, and the heat loss coefficient is $6.9 \%$ lower with PG than with water. When $(\mathrm{m} \bullet \mathrm{Cp})$ is the same between the tests, the average intercept efficiency is $5.9 \%$ lower, and the heat loss coefficient is $9.0 \%$ lower with PG than with water. The larger difference between fluid types suggested by these tests is mostly attributable to the one test with the lowest flow rate of PG. That one test resulted in lower collector performance than would be suggested by the trends of the other tests.

Taken all together, the results indicate that it is not just the fluid $C p$ that causes the difference between the performance of the two fluids, but perhaps other effects such as the difference in viscosity, which would have Reynolds number effects on the internal convection heat transfer coefficients.

We observed that the scatter (repeatability) in the test results is higher at low flow rates with $50 \%$ PG than it is with water. We can speculate that the increased variability is due to the sensitivity of the PG solution to Reynolds number effects, due to the higher viscosity of PG compared to water. The forced convection heat transfer coefficient on the inside of the fluid channels in the collector will be more sensitive to viscosity at the lower flow rates, where the Reynolds number is closer to the transition between laminar and turbulent flow.

\section{Summary of test results}

The full range of all the test results is shown in the efficiency curve plots in Figure 2.7.

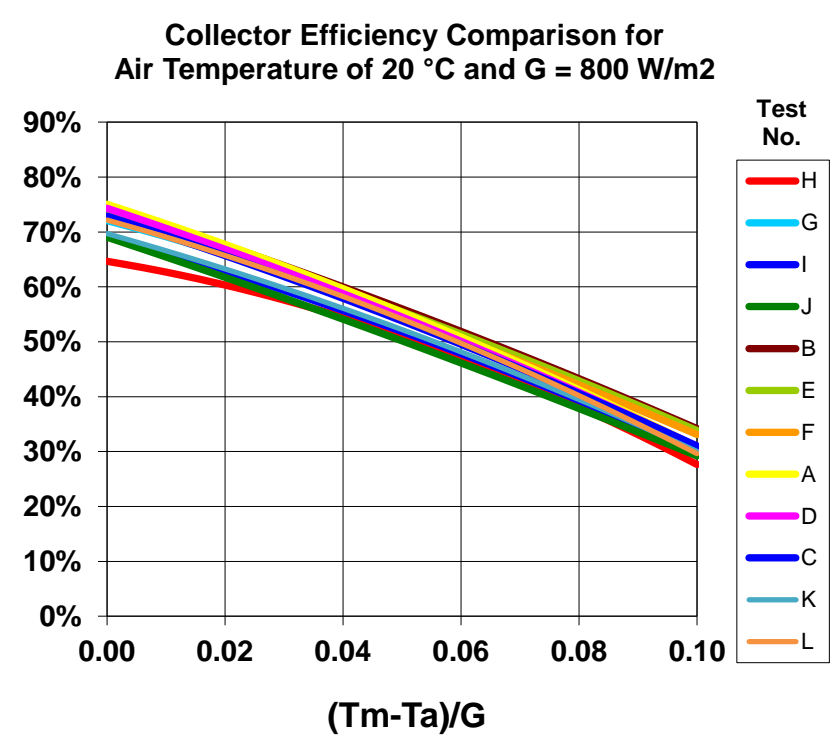

Figure 2.7: Measured collector efficiency curves for all tests combined. 


\section{Correction of collector efficiency depending on fluid type,} flow rate and collector tilt

IEA-SHC TECH SHEET 45.A.1, page 11 of 21

Taking the linear efficiency equations as the basis for comparison, the full range of intercept efficiency is $22 \%$ of the mean, and the full range of heat loss coefficients is $25 \%$ of the mean. This is broken down into the separate effects of fluid type, collector tilt angle and heat transfer fluid flow rate in Table 2.2.

Table 2.2: Magnitude of effects of fluid type, tilt angle and flow rate on collector performance for the range of parameter variations in this study.

\begin{tabular}{|l|l|l|}
\hline Parameter & Effect on $\eta_{\mathbf{o}}$ & Effect on $\mathbf{U}_{\mathbf{L}}$ \\
\hline Fluid Type & $\begin{array}{l}5.9 \% \text { when }(\mathrm{m} \bullet \mathrm{Cp}) \text { is constant } \\
5.3 \% \text { when mass flow is constant }\end{array}$ & $\begin{array}{l}9.0 \% \text { when }(\mathrm{m} \bullet \mathrm{Cp}) \text { is constant } \\
6.9 \% \text { when mass flow is constant }\end{array}$ \\
\hline Collector Tilt & $0.7 \%$ & $7 \%$ \\
\hline Mass Flow Rate & $\begin{array}{l}1.7 \% \text { for water } \\
5.8 \% \text { for } 50 \% \text { PG }\end{array}$ & $\begin{array}{l}0.4 \% \text { for water } \\
3.6 \% \text { for } 50 \% \text { PG }\end{array}$ \\
\hline
\end{tabular}

The analysis of the test results has shown that the largest effect is due to type of heat transfer fluid used, followed by tilt angle. When collector efficiency is expressed as a function of reduced temperature based on mean fluid temperature, the effect of fluid flow rate is small, except where a change in flow rate would cause a transition from laminar to turbulent flow in the fluid passages of the collector.

The details of the linear and second order fits to the data for all of the tests in this study are listed in Table 2.3.

Table 2.3: Summary of all test results.

\begin{tabular}{|c|c|c|c|c|c|c|c|c|c|}
\hline Test & Test & Flow Rate & Flow Rate & Tilt & \multicolumn{3}{|c|}{ Linear Eqn. } & \multicolumn{3}{|c|}{ 2nd Order Eqn. } \\
\cline { 7 - 11 } & Fluid & $\begin{array}{c}\text { (L/min per } \\
\text { collector) }\end{array}$ & $\begin{array}{c}\text { (Kg/s per } \\
\text { collector) }\end{array}$ & Angle & $\eta_{\mathbf{o}^{*}}$ & $\mathbf{a}_{\mathbf{1}}{ }^{*}$ & $\eta_{\mathbf{0}}$ & $\mathbf{a}_{\mathbf{1}}$ & $\mathbf{a}_{\mathbf{2}}$ \\
\hline C & Water & 0.62 & 0.0101 & 60 & 0.745 & 4.220 & 0.729 & 3.450 & 0.0092 \\
\hline D & Water & 1.22 & 0.0200 & 60 & 0.755 & 4.296 & 0.743 & 3.583 & 0.0095 \\
\hline A & Water & 3.48 & 0.0571 & 60 & 0.759 & 4.242 & 0.750 & 3.457 & 0.0120 \\
\hline F & Water & 0.61 & 0.0100 & 90 & 0.742 & 3.995 & 0.727 & 3.263 & 0.0087 \\
\hline E & Water & 1.21 & 0.0199 & 90 & 0.748 & 3.961 & 0.738 & 3.339 & 0.0082 \\
\hline B & Water & 3.48 & 0.0571 & 90 & 0.753 & 3.939 & 0.747 & 3.429 & 0.0078 \\
\hline J & $50 \%$ PG & 0.58 & 0.0098 & 60 & 0.700 & 4.013 & 0.691 & 3.569 & 0.0052 \\
\hline I & $50 \%$ PG & 1.16 & 0.0197 & 60 & 0.706 & 3.879 & 0.692 & 3.006 & 0.0114 \\
\hline G & $50 \%$ PG & 3.34 & 0.0569 & 60 & 0.735 & 4.012 & 0.721 & 2.801 & 0.0183 \\
\hline H & $50 \%$ PG & 0.66 & 0.0112 & 60 & 0.686 & 3.736 & 0.647 & 1.777 & 0.0240 \\
\hline K & $50 \%$ PG & 1.32 & 0.0224 & 60 & 0.711 & 3.903 & 0.697 & 3.025 & 0.0118 \\
\hline L & $50 \%$ PG & 3.79 & 0.0647 & 60 & 0.733 & 4.019 & 0.722 & 2.964 & 0.0161 \\
\hline
\end{tabular}

\section{Danish investigations}




\section{Correction of collector efficiency depending on fluid type,} flow rate and collector tilt

IEA-SHC TECH SHEET 45.A.1, page 12 of 21

\section{Description of the investigated solar collectors}

The two investigated solar collectors were the models HT-SA 35-10 and HT-A 35-10, manufactured by the Danish company ARCON Solar A/S. These are large scale solar collectors and are normally used in solar collector fields for district heating application in Denmark.

The collectors were largely identical in terms of design and technical specifications and the only relevant difference was a $0.025 \mathrm{~mm}$ thick FEP (Fluorinated Ethylene Propylene) foil. The different appearance of the two collectors can be seen in Figure 3.1.

The collectors were installed beside each other, so that they experienced identical weather conditions. They both had an orientation of $9.5^{\circ}$ West with respect to South, while the tilt angle could be changed through the use of semi-mobile scaffolding. Both collectors had external dimensions of $2.27 \times 5.96 \times 0.14 \mathrm{~m}$ with a total gross area of $13.57 \mathrm{~m}^{2}$, while the aperture area was equal to $12.56 \mathrm{~m}^{2}$. The absorber consisted of 18 aluminium strips covered by a selective coating. Each collector had two manifolds with a diameter of $35 \mathrm{~mm}$, placed vertically along the sides and connected by 18 horizontal copper tubes with a diameter of 10 $\mathrm{mm}$, laser-welded below the absorber strips. The external cover was made of an anti-reflective treated glass with a thickness of $3.2 \mathrm{~mm}$. The insulation consisted of mineral wool, with a thickness of $75 \mathrm{~mm}$ below and $30 \mathrm{~mm}$ along the edges.
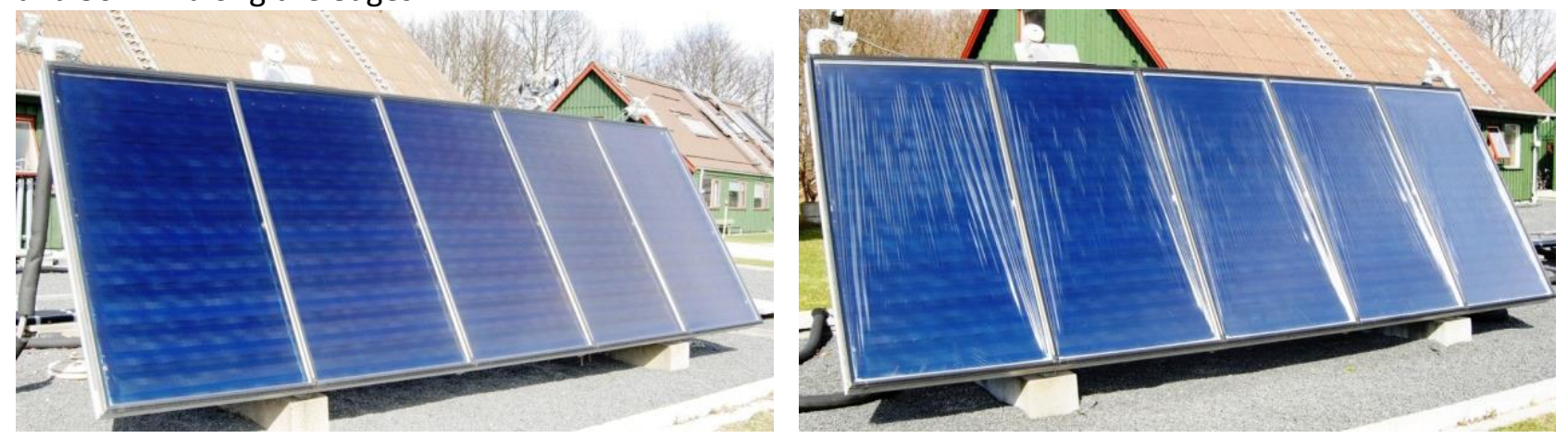

Figure 3.1: Solar collector HT-A 35-10 (left) and HT-SA 35-10 (right) at the Department of Civil Engineering at the Technical University of Denmark.

\section{Test facility and test conditions}

The solar collectors were installed and tested outdoors, in a solar collector test facility at the Technical University of Denmark. The fluid flow rates to the collectors were measured by two electromagnetic flow meters manufactured by Kamstrup (model MP240 and MP115 for the collector HT-A and HT-SA respectively) with an accuracy of $1.5 \%$. The inlet temperatures were measured by type TT thermocouples using a copper-constantan junction, while the temperature differences between outlet and inlet temperature were measured by thermopiles with five copper-constantan junctions at each measuring point. The total radiation on the collector plane was measured independently for each collector by a CM11 pyranometer, produced by Kipp \& Zonen and fulfilling the requirements of the highest accuracy class according to the norm ISO 9060. The diffuse radiation was measured by a similar pyranometer equipped 


\section{Correction of collector efficiency depending on fluid type, flow rate and collector tilt \\ IEA-SHC TECH SHEET 45.A.1, page 13 of 21}

with a shadow band.

The collectors were tested with a tilt angle of $45^{\circ}$ at 5, 10 and 25 litres $\min ^{-1}$ between 2011 and 2012, and then with tilt angles of $30^{\circ}$ and $60^{\circ}$ at 25 litres $\mathrm{min}^{-1}$ in 2013 , using a propylene glycol/water mixture with a $40 \%$ weight concentration as solar collector fluid. Due to damages suffered during wind storms in autumn 2013, the solar collector HT-A became unusable. Hence, the later tests were carried out in the spring and summer 2014 on the original HT-SA collector only, for a tilt angle of $45^{\circ}$, a flow rate of 25 litres min $^{-1}$ and using pure water as solar collector fluid. After completing the measurements on the HT-SA collector, this was opened and its FEP foil removed, in order to make it like a HT-A collector and test it under the same operating conditions.

The collector efficiency expressions were evaluated according to the standard norm EN 12975-2, so at least four independent data points were obtained for at least four different temperature levels, in a range between $20^{\circ} \mathrm{C}$ and $100{ }^{\circ} \mathrm{C}$. These data points were then interpolated by means of regression according to the method of least squares and the collector efficiency was expressed by the equation:

$$
\eta=\eta_{0}-a_{1} \cdot \frac{\left(T_{m}-T_{a}\right)}{G}-a_{2} \cdot \frac{\left(T_{m}-T_{a}\right)^{2}}{G}
$$

where $\eta[-]$ is the collector efficiency, based on the aperture area of the collector,

$\eta_{0}[-]$ is the zero-loss efficiency,

$a_{1}\left[\mathrm{~W} \mathrm{~m}^{-2} \mathrm{~K}^{-1}\right]$ is the first order heat loss coefficient,

$a_{2}\left[\mathrm{~W} \mathrm{~m}^{-2} \mathrm{~K}^{-2}\right]$ is the second order heat loss coefficient,

$T_{m}\left[{ }^{\circ} \mathrm{C}\right]$ is the mean fluid temperature within the solar collector,

$T_{a}\left[{ }^{\circ} \mathrm{C}\right]$ is the ambient temperature,

$G\left[\mathrm{~W} \mathrm{~m}^{-2}\right]$ is the total solar irradiance on the collector plane.

Nevertheless, in case the second order heat loss coefficient $a_{2}$ is negative, the EN norm states that the efficiency expression must be computed in a first order form:

$$
\eta=\eta_{0}-a_{1} \cdot \frac{\left(T_{m}-T_{a}\right)}{G}
$$

The coefficients of the efficiency expressions for the different operating conditions are listed in Table 3.2.

Also the incidence angle modifier (IAM) was evaluated according to the test procedure suggested in the norm EN 12975-2, but the tangent formula (Eq. 3.1) was used in place of the cosine formula, as the former proved to fit the experimental data more accurately than the latter.

$$
I A M=1-\tan ^{p}\left(\frac{\Theta}{2}\right) \quad \text { (Eq. 3.1) }
$$

where $\Theta i s$ the angle of incidence,

$p[-]$ is the characteristic coefficient. 


\section{Correction of collector efficiency depending on fluid type, flow rate and collector tilt IEA-SHC TECH SHEET 45.A.1, page 14 of 21}

\section{Influence of the FEP foil on the collector efficiency}

As can be noted from the experimental values zero-loss efficiency (Table 3.2) and Figures 3.2, 3.3 and 3.4, the presence of the FEP foil negatively affected the transmittance of the collector cover, causing a decrease in the zero-loss efficiency. On the other hand, neither the tilt angle nor the fluid flow rate had a major influence on the zero-loss efficiency. So, when supplied with a relatively cold fluid, the HT-A collector performed better than the HT-SA model. However, as the heat losses were lower in the HT-SA collector, the efficiency difference between the two models decreased with increasing mean temperatures until it became null for a certain value of reduced mean temperature. At this stage, any further increase in temperature entailed a better performance of the HT-SA collector with respect to the HT-A. As the fluid temperature generally increases from relatively low $\left(\sim 40{ }^{\circ} \mathrm{C}\right)$ to relatively high values $\left(\sim 85{ }^{\circ} \mathrm{C}\right)$ along a collector array in a solar heating field, a mixed composition of solar collectors with and without FEP foil seems to be the best solution, using collectors without foil in the first part of the array and collectors with foil in the second part, in order to optimally exploit their different characteristics.

\section{Collector efficiencies for different volume flow rates}

The two collectors were tested with propylene glycol/water mixture at different flow rates and constant tilt angle of $45^{\circ}$. The chosen flow rates were 5,10 and 25 litres $\mathrm{min}^{-1}$. The higher flow rate of 25 litres $\mathrm{min}^{-1}$ is in agreement with the recommendations prescribed by the standard EN 12975-2, which states that the fluid flow rate should be approximately $1.2 \mathrm{~kg} \mathrm{~min}^{-1}$ per unit aperture area of solar collector. In 2011, when these collectors were installed, collector rows in Danish solar heating field consisted of a lower number of collectors and 25 litres $\mathrm{min}^{-1}$ was the nominal flow rate in normal operating conditions. Nevertheless, lower flow rates were used in the early morning and late afternoon, or generally whenever the solar irradiance was not sufficiently high, in order to be able to reach high return temperatures from the solar collector field. For this reason, flow rates of 5 and 10 litres $\mathrm{min}^{-1}$ were tested beside 25 litres $\mathrm{min}^{-1}$. 


\section{Correction of collector efficiency depending on fluid type,} flow rate and collector tilt

IEA-SHC TECH SHEET 45.A.1, page 15 of 21

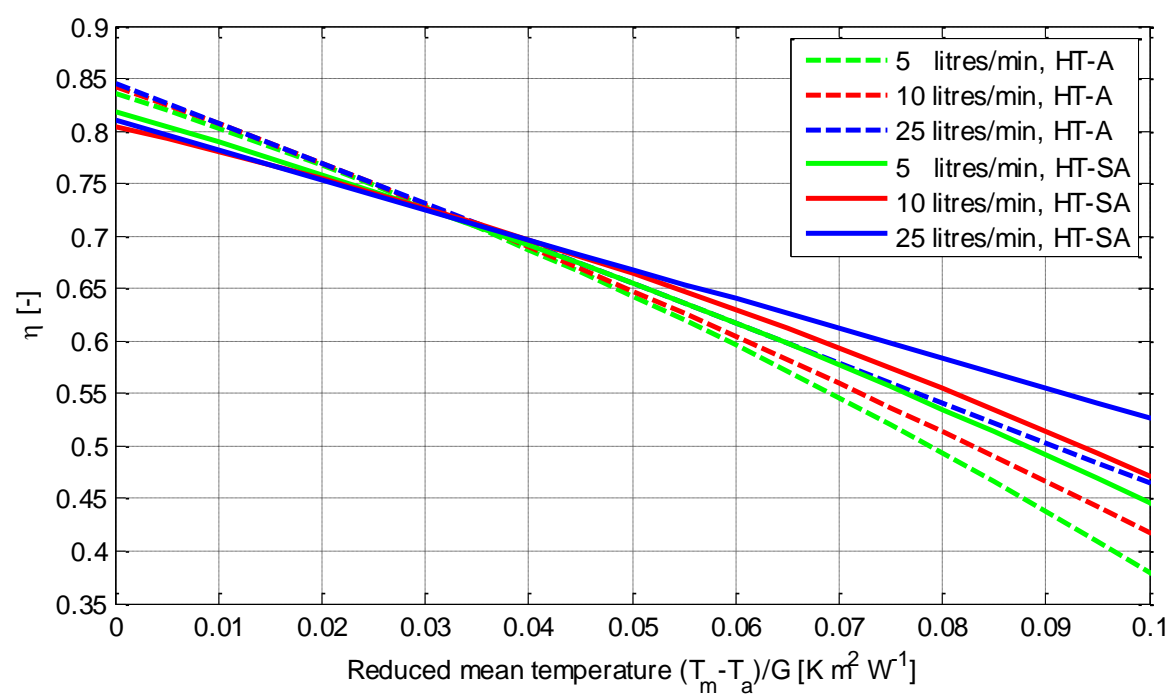

Figure 3.2: Efficiency curves for the HT collectors at different flow rates, $45^{\circ}$ tilt and total solar irradiance $\mathrm{G}=1000 \mathrm{~W} \mathrm{~m}^{-2}$.

As can be noted from the efficiency coefficients in Table 3.2 and seen in Figure 3.2, the efficiency expressions for 5 and 10 litres $\mathrm{min}^{-1}$ had the usual quadratic form, while those found for a flow rate of 25 litres $\min ^{-1}$ were linear. Analysing the single efficiency data points (Figures 4.1 and 4.2), it was found that the efficiencies measured at the highest temperature level were the main reason for the bending of the curves in the 5 and 10 litres $\mathrm{min}^{-1}$ cases, while efficiencies calculated at lower temperatures were largely aligned. This result was most likely due to the fact that heat losses in a solar collector increase more than linearly with the temperature difference between fluid and external environment, due to the radiation contribution (which becomes increasingly important at higher temperatures), the convection losses (which increase due to the lower viscosity of air between absorber and cover) and secondarily the conduction losses, as the thermal conductivity of mineral wool increases with temperature. Conversely, no bending appeared in the diagrams regarding 25 litres $\mathrm{min}^{-1}$ flow rate. The reason of this unexpected behaviour was found in the combination of high fluid velocity and low kinematic viscosity at the highest temperature level, resulting in large Reynolds numbers (Re $\approx 3800-6300$ ) and turbulent flow regime. This different flow regime led to a much higher heat transfer coefficient than laminar flow and hence was able to counteract the increased thermal losses. If measurements at higher temperature levels had been taken, a quadratic form of the efficiency expression would most likely have been found for 25 litres $\operatorname{~min}^{-1}$ flow rate as well. Much attention should be paid when using these linear equations outside the temperature range for which they were calculated, because extrapolation of the curves for higher values of the ratio $\left(T_{m}-T_{a}\right) / G$ would most likely overestimate the actual efficiency of the collectors.

\section{Collector efficiencies for different collector tilt angles}

The two collectors were also tested with propylene glycol/water mixture at different tilt angles, more specifically at $30^{\circ}, 45^{\circ}$ and $60^{\circ}$. The angles of $30^{\circ}$ and $45^{\circ}$ were chosen as they are respectively the lower and upper tilt angle usually adopted in solar collector fields in Denmark (Furbo et al., 2014). On the other 


\section{Correction of collector efficiency depending on fluid type,} flow rate and collector tilt

IEA-SHC TECH SHEET 45.A.1, page 16 of 21

hand, the angle of $60^{\circ}$ was chosen as this is the tilt commonly used by test institutes when assessing the collector efficiency to be reported in the collector data sheet.

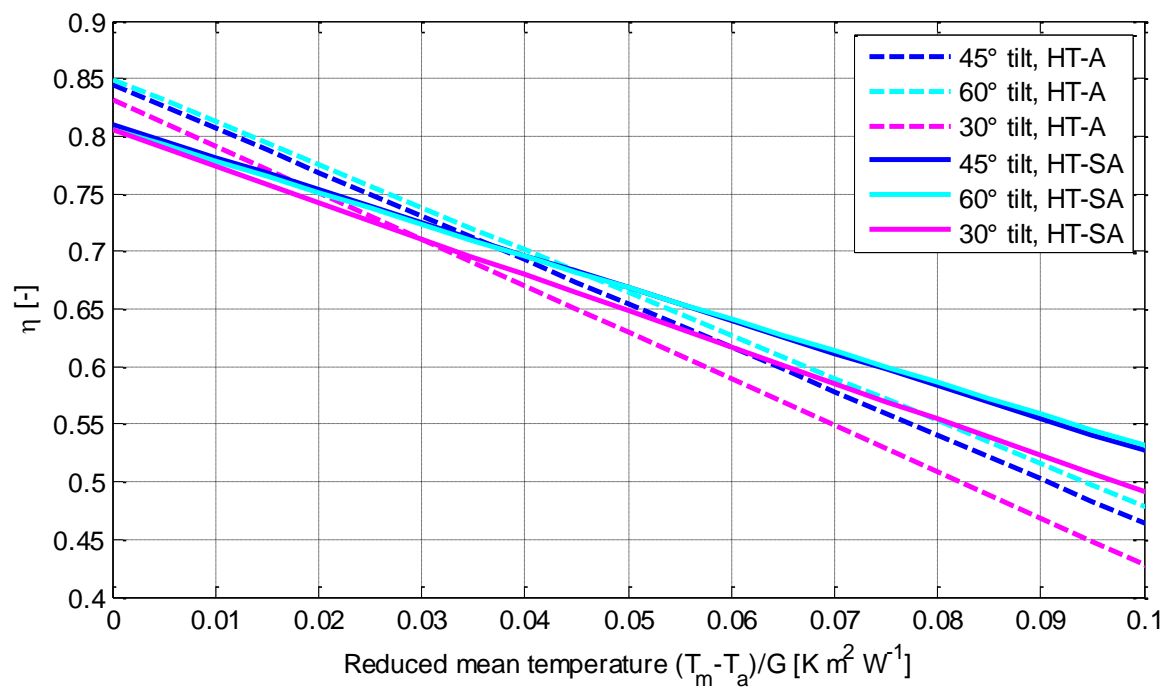

Figure 3.3: Efficiencies curves for the HT collectors at different tilt angles and 25 litres min $^{-1}$.

From Figure 3.3, it is seen that the larger the tilt angle, the higher the efficiency, due to the lower heat loss coefficient. The exact values of heat loss coefficients for the different tilt angles can be read in Table 3.2. From both Figure 3.3 and Table 3.2, it can be noted that the relation between tilt angle and efficiency was not linear for either of the collectors. In fact, taking $45^{\circ}$ tilt as a reference, decreasing the angle to $30^{\circ}$ ($33 \%$ ) caused an increase in the first order heat loss coefficient by $6.3 \%$ and $10.6 \%$ for the collector HT-A and HT-SA respectively. On the other hand, a tilt of $60^{\circ}(+33 \%)$ caused the same coefficient to decrease by only $2.4 \%$ and $3.2 \%$ for the collector HT-A and HT-SA respectively. In fact, in Figure 3.3 it is clear that the efficiency curves for the $45^{\circ}$ and $60^{\circ}$ tilt angles are very close to each other compared to those at $45^{\circ}$ and $30^{\circ}$ tilt.

This effect of the tilt angle on the heat losses is in agreement with theory, as both radiation and convection losses are expected to decrease when tilting a flat plate collector. In fact, when a collector is tilted, the view factor of the aperture area toward the earth surface increases, while the view factor toward the sky is reduced. Since the radiation temperature of the sky is lower than that of the earth, a higher tilt positively affects the efficiency by reducing the radiation losses. Convective losses also decrease due to the reduced number of convective cells between the absorber and cover.

\section{Collector efficiencies for different solar collector fluids}

A mixture of propylene glycol and water is the most common fluid used in this kind of solar collectors, when they are installed in solar collector fields. Mixtures of propylene glycol and water have the advantage of being characterized by lower freezing temperatures and higher boiling points than pure water. So, they can successfully be used to avoid freezing of the fluid inside the collectors in winter and to reduce the risk 


\section{Correction of collector efficiency depending on fluid type,} flow rate and collector tilt

IEA-SHC TECH SHEET 45.A.1, page 17 of 21

of boiling and consequent stagnation. On the other hand, these mixtures present some drawbacks, such as lower specific heat per unit volume, higher viscosity (which negatively affects both the convective heat transfer coefficient and the pressure drop) and higher cost.

Although propylene glycol/water mixtures are used in solar collector fields, the collector efficiency stated in the technical data sheets usually refers to water as collector fluid. Given the better characteristics of water as collector fluid, it is of interest to know how much the fluid type influences the collector performance. For this reason, the two HT collectors were also tested using water as solar collector fluid, while supplied by a flow rate of 25 litres $\min ^{-1}$ and tilted by $45^{\circ}$. The corresponding efficiency curves and the single efficiency data points can be seen in Figure 3.4. As comparison, the same figure also shows the efficiency data points obtained for a 25 litres $\mathrm{min}^{-1}$ flow rate of $40 \%$ glycol/water mixture and $45^{\circ}$ tilt. A point-to-point comparison was preferred to a curve-to-curve comparison, because quadratic best fit curves obtained from efficiency points with different flow regime may be difficult to be compared properly.

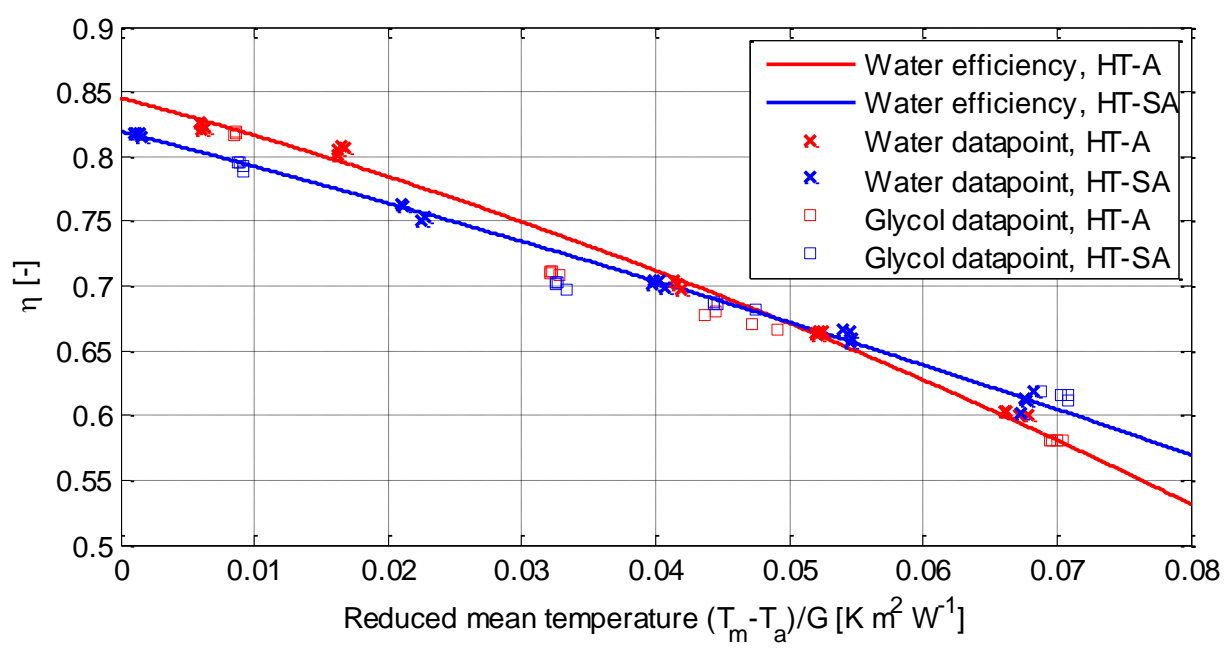

Figure 3.4: Efficiencies curves and efficiency data points (cross markers) using water in the HT collectors at $45^{\circ}$ tilt angle and 25 litres $\mathrm{min}^{-1}$. Square markers are the efficiency data points for glycol/water mixture at $45^{\circ}$ tilt angle and 25 litres $\mathrm{min}^{-1}$.

\section{Incidence angle modifier}

The IAM was measured in all the different operating conditions and the values of the $p$ exponent are listed in Table 3.1. Despite the scattered values, characterized by similar standard deviation $(0.12$ and 0.10 for the collector HT-A and HT-SA respectively), the results showed clearly that the presence of the FEP foil reduced the optical properties of the cover, as the HT-A collector had a higher IAM curve than the HT-SA model in every operating condition. On the other hand, tilt angle and flow rate did not appear to influence the IAM in a specific way, so that if a single value of the $p$ exponent needed to be chosen, the simplest approximation would consist in using the arithmetic mean, which is equal to 3.9 and 3.6 for the solar collector HT-A and HT-SA respectively. 


\section{Correction of collector efficiency depending on fluid type, flow rate and collector tilt \\ IEA-SHC TECH SHEET 45.A.1, page 18 of 21}

\begin{tabular}{|c|c|c|c|c|}
\hline \multirow{2}{*}{$\begin{array}{c}\text { Tilt angle } \\
{\left[^{\circ}\right]}\end{array}$} & \multirow{2}{*}{$\begin{array}{c}\text { Flow rate } \\
{\left[\text { litres } \mathrm{min}^{-1}\right]}\end{array}$} & \multirow[t]{2}{*}{ Fluid type } & \multicolumn{2}{|c|}{$p$ exponent } \\
\hline & & & HT-A & HT-SA \\
\hline $45^{\circ}$ & 5 & $40 \%$ glycol & 4.08 & 3.65 \\
\hline $45^{\circ}$ & 10 & $40 \%$ glycol & 3.73 & 3.37 \\
\hline $45^{\circ}$ & 25 & $40 \%$ glycol & 3.78 & 3.60 \\
\hline $60^{\circ}$ & 25 & $40 \%$ glycol & 3.96 & 3.65 \\
\hline $30^{\circ}$ & 25 & $40 \%$ glycol & 3.77 & 3.57 \\
\hline $45^{\circ}$ & 25 & water & 3.80 & 3.67 \\
\hline \multicolumn{2}{|c|}{ Mean } & & 3.85 & 3.58 \\
\hline \multicolumn{2}{|c|}{ Standard deviation } & & 0.12 & 0.10 \\
\hline
\end{tabular}

Summary of test results and magnitude of the effect of the operating conditions on the efficiency parameters

A comprehensive and compact overview of the efficiency test results for all the tested operating conditions is given in Table 3.2. As explained in the previous sections, the effect of the presence of the FEP foil on the zero-loss efficiency and on the heat losses, the influence of the tilt angle, flow rate and fluid type on the efficiency parameters can here be assessed in a quantitative way.

Table 3.2: Summary of test results.

\begin{tabular}{ccccccc}
\hline $\begin{array}{c}\text { Collector } \\
\text { model }\end{array}$ & $\begin{array}{c}\text { Fluid } \\
\text { type }\end{array}$ & $\begin{array}{c}\text { Flow rate } \\
{\left[\text { [itres } \mathrm{min}^{-1}\right]}\end{array}$ & $\begin{array}{c}\text { Tilt } \\
{\left[{ }^{\circ}\right]}\end{array}$ & $\begin{array}{c}\eta_{0} \\
{[-]}\end{array}$ & $\begin{array}{c}\mathbf{a}_{1} \\
{\left[\mathrm{~W} \mathrm{~m}^{-2} \mathrm{~K}^{-1}\right]}\end{array}$ & $\begin{array}{c}\mathbf{a}_{2} \\
{\left[\mathrm{~W} \mathrm{~m}^{-2} \mathrm{~K}^{-2}\right]}\end{array}$ \\
\hline HT-A & $40 \%$ glycol & 5 & 45 & 0.835 & 3.13 & 0.0143 \\
\hline HT-A & $40 \%$ glycol & 10 & 45 & 0.843 & 3.55 & 0.0070 \\
\hline HT-A & $40 \%$ glycol & 25 & 45 & 0.845 & 3.80 & - \\
\hline HT-A & $40 \%$ glycol & 25 & 60 & 0.850 & 3.71 & - \\
\hline HT-A & $40 \%$ glycol & 25 & 30 & 0.832 & 4.04 & - \\
\hline HT-A & water & 25 & 45 & 0.845 & 2.75 & 0.0146 \\
\hline HT-SA & $40 \%$ glycol & 5 & 45 & 0.818 & 2.76 & 0.0096 \\
\hline HT-SA & $40 \%$ glycol & 10 & 45 & 0.804 & 2.26 & 0.0107 \\
\hline HT-SA & $40 \%$ glycol & 25 & 45 & 0.810 & 2.83 & - \\
\hline HT-SA & $40 \%$ glycol & 25 & 60 & 0.806 & 2.74 & - \\
\hline HT-SA & $40 \%$ glycol & 25 & 30 & 0.805 & 3.13 & - \\
\hline
\end{tabular}




\section{Correction of collector efficiency depending on fluid type, flow rate and collector tilt \\ IEA-SHC TECH SHEET 45.A.1, page 19 of 21}

\begin{tabular}{lllllll}
\hline HT-SA & water & 25 & 45 & 0.820 & 2.66 & 0.0057 \\
\hline
\end{tabular}

Direct comparison of the efficiency curves can be done, when no change in flow regime occurs throughout the temperature range at which the collectors are tested: for example 5 and 10 litres min $^{-1}$ flow rates in this study. On the other hand, when the flow regime switches from laminar to turbulent across the investigated temperature range, a change in the profile of the efficiency curve occurs and a simple quadratic expression cannot interpolate the data accurately. In these cases the slope of the efficiency curve and secondarily the zero-loss efficiency are affected by the amount of points taken in the three different flow regime conditions and by the temperature level at which regime transition occurs. Consequently, much attention should be paid in drawing conclusions regarding the efficiency expression parameters, and a point-by-point analysis is more advisable. Alternatively, and in case enough measurement points are available, the efficiency points may be grouped according to different flow regime conditions and the regression done on each subgroup.

A solar collector efficiency calculation program Soleff is used to investigate the influence of fluid types, tilt angle and flow rate on collector efficiency. The result is shown in Table 3.3. In order to be able to compare different heat loss coefficients when the second order term is null, a new heat loss coefficient, $U_{L}$, is defined according to the following equation:

$$
U_{L}=a_{1}+a_{2} \cdot\left(T_{m}-T_{a}\right)
$$

where a mean fluid temperature $T_{m}$ of $65^{\circ} \mathrm{C}$ and an ambient temperature $T_{a}$ of $15^{\circ} \mathrm{C}$ were assumed.

Table 3.3: Magnitude of effects of fluid type, tilt angle and flow rate on collector efficiency for the range of parameter variations in this study.

\begin{tabular}{lcc}
\hline Parameter & Effect on n $_{0}$ & Effect on $\mathbf{U}_{\mathbf{L}}$ \\
\hline Fluid type & $\begin{array}{c}0 \% \text { (same regime) } \\
4 \% \text { (different regime) }\end{array}$ & $2 \%$ \\
\hline Collector tilt & $1 \%$ & $5 \%-8 \%$ \\
\hline Volume flow rate & $2 \%$ (same regime) & $\begin{array}{c}1 \% \text { (same regime) } \\
3 \% \text { (different regime) }\end{array}$ \\
\hline
\end{tabular}

In case of fluid type water and glycol/water mixture are compared only for the common flow rate of 25 litres $\mathrm{min}^{-1}$ and the common tilt angle of $45^{\circ}$. For the collector tilt influence, the deviation was calculated between the higher $\left(60^{\circ}\right)$ and the lower $\left(30^{\circ}\right)$ value of angle for the glycol/water mixture and the flow rate of 25 litres $\mathrm{min}^{-1}$. For the flow rate influence, the deviation was calculated between the higher ( 25 litres $\mathrm{min}^{-1}$ ) and the lower (5 litres $\mathrm{min}^{-1}$ ) value for the glycol/water mixture and the collector tilt of $45^{\circ}$.

As can be read from Table 3.3, the zero-loss efficiency is not significantly affected by the collector tilt and the flow rate, as long as this does not entail a change in flow regime. The fluid type itself does not affect the 


\section{Correction of collector efficiency depending on fluid type, flow rate and collector tilt \\ IEA-SHC TECH SHEET 45.A.1, page 20 of 21}

zero-loss efficiency, unless the different fluids in use (water and glycol/water mixture) experience different flow regime. This can be explained by the fact that, being the zero-loss efficiency evaluated in case of null losses, the difference in $\left(\rho \cdot c_{p}\right)$ of the two fluids plays no role. Additionally, if both fluids are in laminar conditions due to the low temperature, the heat transfer coefficient within the absorber pipe is not affected by the different viscosities of the two fluids. On the other hand, if the difference in fluid entails a difference in flow regime, the effect on the zero-loss efficiency is about $4 \%$. Regarding the effect on the heat loss coefficient, $U_{L}$, the most important parameter is the tilt angle, which causes a change of 5\%-8\%. Compared to the tilt angle, both fluid type and flow rate have a minor influence on the heat losses.

\section{Conclusions and recommendation for future test standards for solar collectors}

Investigations of different flat plate solar collectors showed that the solar collector efficiency is influenced by the solar collector fluid, the collector tilt and the volume flow rate. The collector efficiency is increased by:

- decreasing the percentage of glycol of the glycol/water mixture used as solar collector fluid

- increasing the collector tilt

- increasing the volume flow rate

It has been shown that flow regime (laminar or turbulent) has an important influence on both the thermal performance of a liquid-heating collector and on the ability to accurately predict collector performance. Differences between predicted efficiency based on current standard test conditions and actual performance in the field can be expected to be in the range of 6 to $11 \%$. It is therefore recommended that test conditions used by test institutes under collector tests are as close as possible to the conditions used under operation of the solar collectors.

Solar collectors should be designed and manufactured already thinking which kind of fluid, flow rates and temperatures they will be operated at, so that the absorber pipes can be properly sized to achieve turbulent conditions most of the times. To achieve this goal, the Reynolds number in the pipes should be larger than 4000. If the fluid type and the range of flow rates which will be used in the solar collector loop are known, it is possible to calculate the diameter of the absorber pipes which guarantees turbulence. This recommended diameter can be calculated through equation (Eq. 6.1), making explicit the correlation defining the Reynolds number.

$$
D=\frac{4 V^{\prime}}{\operatorname{Re} \pi n v}
$$

where $D[\mathrm{~m}]$ is the recommended pipe diameter for the absorber pipes,

$V^{\prime}\left[\mathrm{m}^{3} \mathrm{~s}^{-1}\right]$ is the fluid flow rate through to the collector,

$\operatorname{Re}[-]$ is the desired Reynolds number $(\operatorname{Re}=4000)$,

$n[-]$ is the number of parallel absorber pipes, 


\section{Correction of collector efficiency depending on fluid type, flow rate and collector tilt \\ IEA-SHC TECH SHEET 45.A.1, page 21 of 21}

$v\left[\mathrm{~m}^{2} \mathrm{~s}^{-1}\right]$ is the kinematic viscosity of the collector fluid, which should be provided by the manufacturer

Regarding (Eq. 6.1), a uniform flow distribution is assumed. This is obviously a simplification, but can be considered acceptable for large solar collectors like ARCON HT models. In fact, in this case the absorber pipes are much longer and thinner than the manifolds, so that they are responsible for most of the pressure drop across the collector. Another consideration is that, as the viscosity decreases strongly with the temperature, also the recommended diameter will vary. In practise, the diameter should be calculated from (Eq. 6.1) assuming the lowest temperature which is expected in the collector loop, so that turbulence is achieved for any other operation temperature. For similar reasons, also the flow rate used for the calculation should be the lowest operation flow rate which is expected to be used. After calculating the recommended diameter, it is advisable to check that the consequent pressure losses are acceptable.

Concerning the procedure to measure the efficiency, changes in flow regime within the investigated temperature range should be avoided, as they would affect the trend of the interpolating curve. Only single efficiency points which are characterized by the same flow regime should be interpolated. In case the transition from laminar to turbulent condition occurs at a temperature lower than the operation temperature range at which the collector operates at, then the efficiency curve could be obtained only considering the relevant temperature interval, neglecting the lower temperature level where transition occurs. In this way, a better fit can be obtained without loss of relevant information. Large solar collectors for district heating application can be an example. In such installation the inlet temperature to the collector field is approximately equal to the return temperature from the district heating network $\left(40-50{ }^{\circ} \mathrm{C}\right)$. Consequently, it is not particularly relevant to investigate the collector efficiency for lower temperatures.

\section{References}

Arcon Solar A/S, 2010. ARCON solfanger - type HT-SA 35/10.

Chiou, J. P., 1982. The effect of non-uniform fluid flow distribution on the thermal performance of solar collector. Solar Energy 6, 487-502.

Fan, J., Furbo, S., 2008. Buoyancy effects on thermal behavior of a flat-plate solar collector. Journal of Solar Energy Engineering 130.

Furbo, S., Holck, O., 1995. Efficiencies of solar collectors for different tilts. Measurements. Report SR 95-7, Thermal Insulation Laboratory, Technical University of Denmark.

Furbo, S., Perers, B., Bava, F., 2014. Thermal performance of solar district heating plants in Denmark, in EuroSun 2014 Conference Proceedings, Aix-les-Bains, France.

SP Technical Research Institute of Sweden, 2011. Technical Report Ref. PX12871-01.

Rasmussen, P.B., Svendsen, S., 1996. SolEff Program til beregning af solfangeres effektivitet. Thermal Insulation Laboratory, Technical University of Denmark.

Wang, X. A., Wu, L. G., 1990. Analysis and performance of flat plate solar collector arrays. Solar Energy 2, 71-78. 